\title{
Antibiotics' Prescribing and Pharmacovigilance Attitudes among Pediatricians and Pediatric Residents in Cyprus
}

\author{
Mary Geitona $^{1}$, Aikaterini Toska ${ }^{1}$, Dimitra Latsou${ }^{1}$, Maria Saridi' ${ }^{1}$, Andri Evripidou ${ }^{2}$, \\ Iliada Evripidou ${ }^{2}$ \\ ${ }^{1}$ Department of Social \& Educational Policy, University of Peloponnese, Corinth, Greece \\ ${ }^{2}$ University of Neapolis, Pafos, Cyprus \\ Email: ktoska07@yahoo.gr
}

How to cite this paper: Geitona, M., Toska, A., Latsou, D., Saridi, M., Evripidou, A. and Evripidou, I. (2017) Antibiotics' Prescribing and Pharmacovigilance Attitudes among Pediatricians and Pediatric Residents in Cyprus. Pharmacology \& Pharmacy, 8, 75-84.

https://doi.org/10.4236/pp.2017.83005

Received: January 23, 2017

Accepted: March 11, 2017

Published: March 14, 2017

Copyright $\odot 2017$ by authors and Scientific Research Publishing Inc. This work is licensed under the Creative Commons Attribution International License (CC BY 4.0).

http://creativecommons.org/licenses/by/4.0/

\begin{abstract}
Background: The inappropriate, irrational use or misuse of antibiotics is observed in all health systems and in all patients' groups worldwide, especially for children, where antibiotics continue to be the drugs most commonly prescribed. Methods: A cross-sectional study was conducted in all public pediatric clinics in the Republic of Cyprus, from April to May 2015. A questionnaire was distributed to pediatricians in order to identify the antibiotic prescription practices in common childhood diseases and attitudes towards Pharmacovigilance. The SPSS 19.0 was used for the statistical analysis. In total 42 pediatricians and pediatric residents filled out the questionnaire. Results: A significant percentage of the respondents administered empirical therapy for possible group A streptococcus infection (59.5\%), they implemented the "watchful waiting" tactic in acute otitis media (66.7\%), whereas $11.9 \%$ of them administered antibiotics for the prevention of secondary respiratory tract infections. The majority of physicians did not feel diagnostic uncertainty leading to antibiotics prescribing (90.2\%) and their prescribing habits were not influenced by parental demand (80.5\%). Although $23.1 \%$ of physicians observed often/very often Adverse Drug Reactions (ADRs) after antibiotic administration during their clinical practice, however, $47.6 \%$ of the pediatricians declared that they did not report them. Conclusion: Health professionals' continuing education on the use of therapeutic guidelines and protocols and the development of Pharmacovigilance programs could significantly contribute to the avoidance of the misuse of antibiotics in hospital care as well as to health professionals' awareness on rational prescribing.
\end{abstract}

\section{Keywords}

Antibiotics' Prescribing, Pharmacovigilance, Pediatricians, 
Adverse Drug Reactions

\section{Introduction}

Antibiotics play a major role in the treatment of infectious diseases; however there is evidence that they are also used for not indicated viral conditions [1] [2] [3]. The overuse of antibiotics is a serious public health problem and there is a clear correlation between their use and the emergence of resistant bacterial strains both in individual and population level [4] [5].

The inappropriate, irrational use or misuse of antibiotics is observed in all health systems and in all patients' groups worldwide, especially for children where antibiotics continue to be the drugs most commonly prescribed. Antibiotics' overprescribing exposes patients unnecessarily to risk of side-effects without achieving more rapid recovery, increases morbidity and mortality as well as related health care costs [6]. It is estimated that over half of all hospitalized patients are treated with antimicrobial agents accounting for $20 \%-50 \%$ of hospitals' total drug expenditures [6].

Antibiotics are reported as the most troublesome of drugs contributing to approximately 15\% - 16\% of cases of Adverse Drug Reactions (ADRs), mostly related with the frequency of administration that accounts approximately for $23 \%$ of all adverse events recorded [7] [8]. Suspected ADRs should be obligatorily and spontaneously reported by health professionals, patients and pharmaceutical companies to the National Pharmacovigilance Centers of each country [9].

According to the international literature, several socioeconomic, behavioral, professional and organizational factors are related with the inappropriate use of antibiotics and Pharmacovigilance reporting, such as the lack of clinical and continuing training on prescribing and ADRs reporting, diagnostic uncertainty, health professionals' support and supervision, work overload, drug promotion, financial motives, patients' demands, inadequate time for further observation and follow up, the non availability of yellow card etc. [10] [11].

Cyprus is among countries with high antibiotics consumption both in community and hospital sector, ranging from 34.4 DDD (Daily Defined Doses) in 2009 to 29.7 DDD in 2012 (per 1000 inhabitants and per day) [12]. The aim of the present study was to explore hospital pediatricians' practices and attitudes on antibiotics prescribing and Pharmacovigilance issues in Cyprus.

\section{Methods}

A cross-sectional study was conducted from April to May 2015 in all public pediatric clinics in the Republic of Cyprus belonging to university and general hospitals, where 57 pediatricians and pediatric residents were employed. For the conduction of this survey, a prior permission was given by each hospital Committee Research. 


\subsection{Study Instruments}

A standardized questionnaire prior used in Greek [13] [14] was distributed to pediatricians in order to identify the antibiotic prescription practices in common childhood diseases and attitudes towards Pharmacovigilance. The questionnaire was divided into 2 parts. The first part, included demographic data whereas the second included questions on respondents' everyday practices and attitudes related to: prescribing antibiotics in common childhood diseases, the existence of physicians' diagnostic uncertainty as well as Pharmacovigilance issues as ADRs due to antibiotic administration and the reporting rates of these.

Questions were dichotomous with answer choices "often/very often" - "never/ rarely" and others with "yes - no". The method of self-administered questionnaire was implemented for data collection purposes.

\subsection{Ethical Approvals}

Informed consent was taken orally from each participant before start of data collection. Confidentiality was assured by indicating they are not requested to write their name on the questionnaire and by assuring that their responses will not in any way be linked to them.

\subsection{Statistical Analysis}

The survey was based on quantitative methodology. Absolute (n) and relative (\%) frequencies were used for the description of qualitative variables. Mean values and standard deviation (SD) were used for the description of quantitative variable (age). The variables are non-normally distributed and non-parametric test was chosen in order to find the differences. Bivariate analyses between dependent and independent variables were performed using chi-square $\left(\chi^{2}\right)$. Independent variables included type of hospitals and position of employment (experience in pediatric) and dependent variable included questions about administration of antibiotics and Pharmacovigilance issues.

Moreover, an odds ratio chi-square test between binary variables was performed in order to find probabilities. For final interpretation of statistical significance, $P=0.05$ was used. Also, the SPSS 19.0 (Statistical Package for Social Sciences) was used for the statistical analysis [15].

\section{Results}

In total 42 out of 57 pediatricians and pediatric residents filled out the questionnaire ( $\mathrm{RR}=74 \%$ ). $57.1 \%$ of the questionnaires were collected from university hospitals, the majority of the sample (82.9\%) was female and $65.9 \%$ of them were not post graduate qualified. The mean age of the participants was 41.5 years $( \pm 11)$ as shown in Table 1.

Regarding the administration of antibiotics in common childhood diseases, as presented in Figure 1, pediatricians administer often/very often empirical antibiotic therapy in pharyngitis in order to manage a possible streptococcus group 
Table 1. Socio-demographic profile of the sample.

\begin{tabular}{cccc}
\hline \multirow{2}{*}{ Data collection } & & No. & $\%$ \\
\hline \multirow{2}{*}{ Gender } & University hospitals & 24 & 57.1 \\
& General hospitals & 18 & 42.9 \\
& Male & 7 & 17.1 \\
Mean Age $=41.5$ years $( \pm 11)$ & 35 & 82.9 \\
& Fediatricians & & \\
Position of physician in hospital & Pediatric residents & 10 & 25 \\
& No answer & 7 & 16.7 \\
Postgraduate qualifications & MSc, PhD & 14 & 34.1 \\
& None of the above & 28 & 65.9 \\
\hline
\end{tabular}

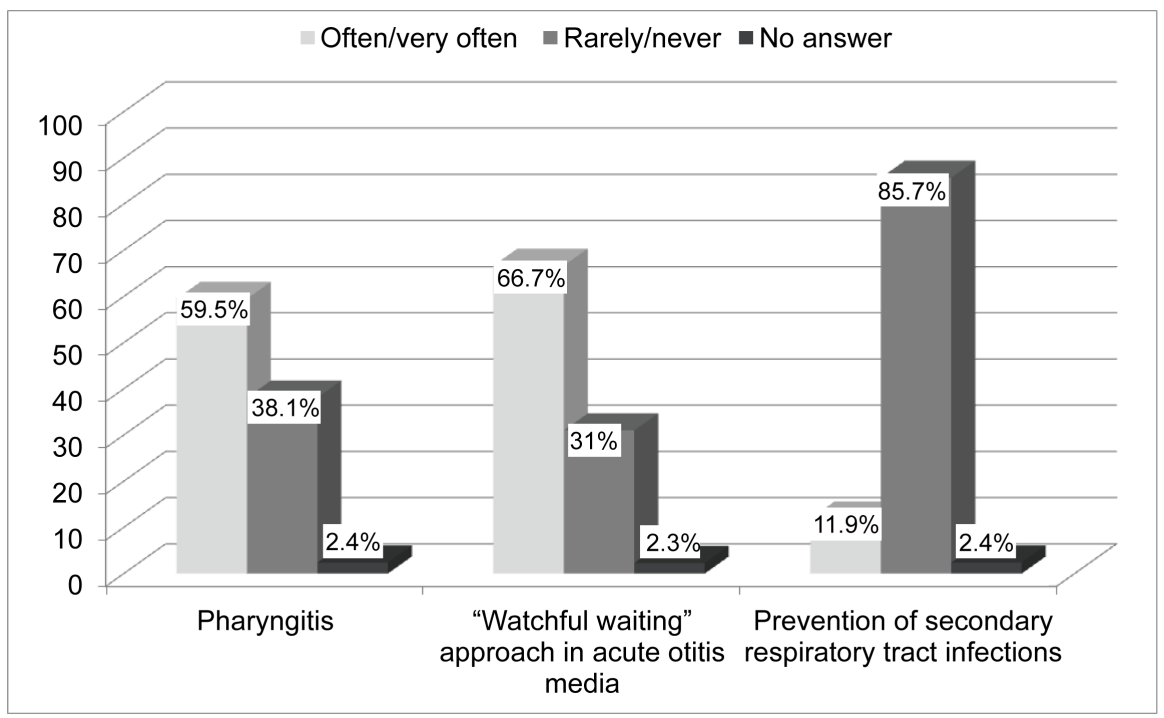

Figure 1. Administration of antibiotics in common childhood diseases.

A infection and implement the "watchful waiting" approach in acute otitis media, However, they administer rarely/never antibiotics for the prevention of secondary respiratory tract infections in children without any other health problems.

The physicians were asked also, if they feel diagnostic uncertainty leading to antibiotic prescribing and in this question the vast majority (90.2\%) answered negatively. Urinary tract infections (35.7\%), otitis (21.4\%) and respiratory tract infections (19\%) were stated as the most important reasons of diagnostic uncertainty. Also, the adoption of special guidelines and protocols (69\%) as well as the use of diagnostic rapid tests (66.7\%) were reported as the most important measures for minimizing diagnostic uncertainty.

Furthermore, $61.9 \%$ of physicians stated that their hospital has internal specialist in infectious diseases who was consulted in cases when a pediatric patient did not respond to the regimen (45\%), when underlying complicated diseases 
were present $(52.4 \%)$, or when patients received a complicated antimicrobial regimen $(42.9 \%)$.

It should be also noted that a significant percentage of the physicians reported an increase in antibiotics use and in parental demand for antibiotic prescribing during the last years, (51.2\% and $40 \%$ respectively). However, the majority of the physicians $(80.5 \%)$ stated that their prescribing habits for antibiotics were rarely or never influenced by parental demand. Moreover, only $38.1 \%$ of the respondents reported that they prescribe antibiotics often/very often based on the low cost of the drugs.

Regarding the Pharmacovigilance issue, $23.1 \%$ of physicians stated that they observe often/very often ADRs after antibiotic administration during their clinical practice. Diarrhea and rash were highlighted as the most important ADRs. (76.2\% and $66.7 \%$ respectively) Amoxicillin and amoxicillin/clavulanic were declared by $40.5 \%$ and $16.7 \%$ of physicians respectively, as the antibiotics which provoke more often ADRs. Nevertheless, $47.6 \%$ of the pediatricians declared that they did not report the experienced ADRs, $45.2 \%$ did it rarely whereas $7.2 \%$ stated that they did it often/very often.

The ADRs reporting to the agent of the pharmaceutical company and the registration in the yellow card scheme were shown as the most commonly used methods according to Table 2. As far as the knowledge about the obligation of reporting, $28.6 \%$ of the respondents answered that all the healthcare workers should report them, $14.3 \%$ stated that only physicians are responsible to report ADRs, 9.5\% reported that this was physicians' and pharmacists' duty, whereas $47.7 \%$ selected the response: "I do not answer/I do not know". Finally, 78.6\% of physicians believed that there is a greater obligation of ADRs reporting in pediatrics compared to the other medical specialties.

As far as the factors affecting the administration of antibiotics, significant differences were found between the administration of empirical therapy in pharyngitis and the position of employment in terms of experience in pediatric. Pediatric residents and physicians employed in general hospitals were 15.2 times (C.I. 2.4 - 95.3) and 5.5 times (C.I. 1.3 - 24.3) more likely to administer often/very often antibiotics for empirical therapy for possible streptococcus group $A$, in comparison with pediatricians $(P=0.001)$ and those employed in university hospitals $(P=0.018)$ respectively. In addition, the presence of an internal specialist in infectious diseases in the university hospitals seems to be 9 times (C.I.

Table 2. Methods of reporting ADRs.

\begin{tabular}{lcc}
\hline & No & $\%$ \\
\hline Yellow Card Scheme & 9 & 21.4 \\
Telephone in Pharmaceutical Services of MoH & 0 & 0 \\
Agent of Pharmaceutical Company & 12 & 28.6 \\
Telephone in Pharmaceutical Company & 1 & 2.4 \\
Nowhere & 20 & 47.6 \\
\hline
\end{tabular}


2.5 - 33.2) more likely compared to the general hospitals $(\mathrm{P}=0.001)$. On the other hand, physicians employed in university hospitals were 1.2 times more likely (C.I. 0.9 - 1.5) to report experienced ADRs compared to those employed in general hospitals $(\mathrm{P}=0.038)$.

\section{Discussion}

To the best of our knowledge, the present study is the first attempt to explore antibiotics prescribing practices and attitudes on Pharmacovigilance of hospital pediatricians in Cyprus. According to our results, a significant proportion of pediatric physicians often prescribe antibiotics in common childhood diseases, they don't feel diagnostic uncertainty and they are not influenced by parental demand for antibiotics administration. The prescribing attitudes of physicians with regards to acute otitis media ( $\mathrm{AOM})$ are in consistent with those reported in the international literature [13] [16]. In these studies, over $60 \%$ of pediatricians implemented the "watchful waiting" practice for the management of AOM, while other studies focusing on hospital and primary health care reported "watchful waiting" rates ranging from $45 \%$ to $50 \%$ [17] [18]. In addition, the often administration of antibiotics in pharyngitis without obtaining throat cultures is also reported by Geitona et al. [13] and Paluck et al. [18] As far as the use of antibiotics for the prevention of secondary respiratory tract infections, our study showed that it was slightly lower than those found in a Greek study [13]. This finding could be considered as satisfying, given that the common respiratory tract infections are the most common causes of antibiotics prescriptions in pediatric care [17] [19].

Urinary tract infections and otitis found in our study as the most common conditions causing greater diagnostic uncertainty related to antibiotic prescribing, are in accordance with Moro et al. findings [17] and in contradiction with Geitona et al., study [13] that highlights respiratory tract infections for diagnostic uncertainty in Greek physicians. The measures indicated in order to reduce diagnostic uncertainty and antibiotic prescribing, such as the use of therapeutic guidelines and diagnostic rapid tests also refer to other international studies [13] [17] [20]. Moreover, the consultation by an infectious diseases specialist has been also found as a measure for reduction antibiotics prescription [16] [17].

Given that the parental demand has been shown that affects antibiotics prescribing both in outpatient [21] [22] [23], and hospital care [13] [16] [24] [25], in this study physicians stated that are rarely or never affected by parental demand. Nevertheless, last year, an increase of the relevant demand is observed, a result which is in agreement with a study conducted in Greece [13]. A positive relationship between prescribing practices and lack of experience in pediatrics reported in several studies [13] [26] [27] is also found in our study. Furthermore, it seems that the prescription of low cost of antibiotic drugs was not taken into consideration by the majority of the Cypriot physicians, a finding similar to other studies [13] [18] however other surveys displayed the cost as an important concern for medication choices [28] [29]. 
As far as the Pharmacovigilance issue, our study revealed that a significant rate of pediatricians experience ADRs related to the administration of antibiotics in their clinical practice, which is in agreement with a relevant Greek study [14]. Also, diarrhea and rash are reported as the most common ADRs following antibiotic administration, and are consistent with the international literature [14] [30] [31] [32] [33] [34]. As far as the responsible antibiotic for the most ADRs, amoxicillin was stated by the majority of physicians, a common finding in several studies [14] [31] [35] [36].

Regarding health professionals' attitudes towards ADRs reporting, our findings revealed that although most physicians experience an ADR in their clinical practice, only a very small percentage reports it officially, a result also displayed in other studies [14] [37]. However, international literature shows higher ADR s reporting rates than those found in our study [37] [38] [39]. Hence, the misbelieve that only serious ADRs are needed to be reported in pediatric care, seems to be the most significant factor of no reporting, highlighted by Sushma et al. [40]. In addition, the physicians' low level of knowledge regarding their obligation of reporting ADRs through the yellow card observed in our study, is in contrary with the results of Kareem et al. reporting higher levels [30].

\section{Limitations}

The subjective response and recall bias, inherent to all questionnaire-based research is a significant limitation of this study.

\section{Conclusion}

Hospital pediatricians in Cyprus usually prescribe antibiotics for common childhood diseases; they do not feel diagnostic uncertainty and are not affected by parental demand on prescribing. Moreover, although ADRs constitutes a reality in their everyday clinical practice, underreporting remains an important public health problem. This attitude is strongly related with the lack of knowledge about their reporting obligation. Health professionals' continuing education on the use of therapeutic guidelines and protocols and the development of Pharmacovigilance programs emphasizing the importance of ADR reporting in pediatrics could significantly contribute to the avoidance of the misuse of antibiotics in hospital care as well as to health professionals' awareness on rational prescribing.

\section{Conflict of Interest}

The authors confirm that this article content has no conflict of interest.

\section{References}

[1] Mollahaliloglu, S., Alkan, A., Donertas, B., Ozgulcu, S. and Akicet, A. (2013) Assessment of Antibiotic Prescribing at Different Hospitals and Primary Health Care Facilities. Saudi Pharmaceutical Journal, 21, 281-291.

https://doi.org/10.1016/j.jsps.2012.10.004 
[2] Viswanad, V., Abraham, S., Abraham, A., Anupama, P.P., Muralidharan, A. and Arya Subash, K. (2010) Confrontational Use of Antibiotics in Pediatric Prescriptions. Deccan Journal of Pharmaceutics \& Cosmetology, 1, 52-56.

[3] Amadeo, B.P., Muller, A., Drapier, N., Vankerckhoven, V., Rogues, A.M., Davey, P. and Goossens, H. (2008) Paediatric Antimicrobial Prescribing in 32 Hospitals of 21 European Countries. Journal of Antimicrobial Chemotherapy, 65, 2247-2252. https://doi.org/10.1093/jac/dkq309

[4] Bronzwaer, S.L., Cars, O., Buchholz, U., Mölstad, S., Goettsch, W., Veldhuijzen, I.K., Jacob, L., Kool, J.L., Sprenger, M.J. and Degener, J.E. (2002) The Relationship between Antimicrobial Use and Antimicrobial Resistance in Europe. Emerging Infectious Diseases, 8, 278-282. https://doi.org/10.3201/eid0803.010192

[5] Goossens, H., Ferech, M., Vander Stichele, R. and Elseviers, M. (2005) Outpatient Antibiotic Use in Europe and Association with Resistance: A Cross-National Database Study. The Lancet, 365, 579-587. https://doi.org/10.1016/S0140-6736(05)70799-6

[6] Shamna, M., Dilip, C., Ajmal, M., Mohan, P., Shinu, C., Jafer, C. and Mohammed, Y. (2014) A Prospective Study on Adverse Drug Reactions of Antibiotics in a Tertiary Care Hospital. Saudi Pharmaceutical Journal, 22, 303-308.

https://doi.org/10.1016/j.jsps.2013.06.004

[7] Granowitz, E.V. and Brown, R.B. (2008) Antibiotic Adverse Reactions and Drug Interactions. Critical Care Clinics, 24, 421-442. https://doi.org/10.1016/j.ccc.2007.12.011

[8] Van Grootheest, K., van Puijenbroek, E.P. and de Jong-van den Berg, L.T. (2004) Do Pharmacists' Reports of Adverse Drug Reactions Reflect Patients' Concerns? Pharmacy World and Science, 26, 155-1459. https://doi.org/10.1023/B:PHAR.0000026802.81401.bb

[9] Morrison-Griffiths, S., Walley, T.J., Park, B.K., et al. (2003) Reporting of Adverse Drug Reactions by Nurses. The Lancet, 361, 1347-1348. https://doi.org/10.1016/S0140-6736(03)13043-7

[10] Abdel-Latif, M.M. and Abdel-Wahab, B.A. (2015) Knowledge and Awareness of Adverse Drug Reactions and Pharmacovigilance Practices among Healthcare Professionals in Al-Madinah Al-Munawwarah, Kingdom of Saudi Arabia. Saudi Pharmaceutical Journal, 23, 154-161. https://doi.org/10.1016/j.jsps.2014.07.005

[11] Suyagh, M., Farah, D. and Farha, R.A. (2015) Pharmacist's Knowledge, Practice and Attitudes toward Pharmacovigilance and Adverse Drug Reactions Reporting Process. Saudi Pharmaceutical Journal, 23, 147-153. https://doi.org/10.1016/j.jsps.2014.07.001

[12] Summary of the Latest Data on Antibiotic Consumption in the EU (2014). http://ecdc.europa.eu/en/eaad/Documents/antibiotics-consumption-EU-data-2014. pdf

[13] Geitona, M., Toska, A., Souliotis, K., Saridi, M. and Demetzos, K. (2015) Antibiotic Prescription Practices of Pediatricians and Pediatric Residents in Hospital Care in Greece. Current Drug Safety, 10, 221-226. https://doi.org/10.2174/1574886310666150602150619

[14] Toska, A., Geitona, M., Souliotis, K., Saridi, M. and Demetzos, K. (2014) Adverse Drug Reaction Reporting Related to the Administration of Antibiotics in Hospitalized Pediatric Patients in Greece. Current Drug Safety, 9, 49-55. https://doi.org/10.2174/15748863113086660064

[15] IBM Corp (2010) IBM SPSS Statistics for Windows. Version 19.0, IBM Corp, Armonk. 
[16] Stille, C.J., Rifas-Shiman, S.L., Kleinman, K. and Kotch, J.B. and Finkelstein, J.A. (2008) Physician Responses to a Community-Level Trial Promoting Judicious Antibiotic Use. Annals of Family Medicine, 6, 206-212. https://doi.org/10.1370/afm.839

[17] Moro, M.L., Marchi, M., Gagliotti, C., Di Mario, S. and Resi, D. (2009) Why Do Pediatricians Prescribe Antibiotics? Results of an Italian Regional Project. BMC Pediatrics, 9, 69. https://doi.org/10.1186/1471-2431-9-69

[18] Paluck, E., Katzenstein, D., Frankish, C.J., Herbert, C.P., Milner, R., Speert, D. and Chambers, K. (2001) Prescribing Practices and Attitudes toward Giving Children Antibiotics. Canadian Family Physician, 47, 521-527.

[19] Yagupsky, P. (2006) Selection of Antibiotic -Resistant Pathogens in the Community. Pediatric Infectious Diseases Society, 25, 974-976. https://doi.org/10.1097/01.inf.0000239270.33190.71

[20] Gervaix, A., Egger, M., Lacroix, L. and Harbarth, S. (2007) Pediatricians' Perception of Antibiotic Use in Children in Two Large Swiss Cities. International Journal of Antimicrobial Agents, 30, 281-283. https://doi.org/10.1016/j.ijantimicag.2007.05.006

[21] Bagshaw, S.M. and Kellner, J.D. (2001) Beliefs and Behaviors of Parents Regarding Antibiotic Use by Children. Canadian Journal of Infectious Diseases, 12, 93-97. https://doi.org/10.1155/2001/250697

[22] Mangione-Smith, R., Elliott, M.N., Stivers, T., McDonald, L.L. and Heritage, J. (2006) Ruling out the Need for Antibiotics: Are We Sending the Right Message? Archives of Pediatrics and Adolescent Medicine, 160, 945-952. https://doi.org/10.1001/archpedi.160.9.945

[23] Panagakou, S., Spyridis, N., Papaevangelou, V., Theodoridou, K., Goutziana, G., Theodoridou, M., Syrogiannopoulos, G. and Hadjichristodoulou, C. (2011) Antibiotic Use for Upper Respiratory Tract Infections in Children: A Cross Sectional Survey of Knowledge, Attitudes and Practices of Parents in Greece. BMC Pediatrics, 11, 60. https://doi.org/10.1186/1471-2431-11-60

[24] Palinke, N. (2004) Prescribing Pattern of Antibiotics in Pediatric Hospital of Kathmandu Valley. Kathmandu University Medical Journal, 2, 6-12.

[25] Bjorkman, I., Berg, J., Roing, M., Erntell, M. and Lundborg, C.S. (2010) Perceptions among Swedish Hospital Physicians on Prescribing of Antibiotics and Antibiotic Resistance. BMJ Quality \& Safety, 19, 1-5. https://doi.org/10.1136/qshc.2008.029199

[26] Bharathiraya, R., Sridharan, S., Chelliah, L.R., Saradha, S. and Mangayarkarasi Senguttuvan Institute of Child Health and Hospital (2005) Factors Affecting Antibiotic Prescribing Pattern in Pediatric Practice. Indian Journal of Pediatrics, 72, 877-879. https://doi.org/10.1007/BF02731121

[27] Garcia, C., LIamocca, L.P., Garcia, K., Jiménez, A., Samalvides, F., Gotuzzo, E. and Jacobs, J. (2011) Knowledge, Attitudes and Practice Survey about Antimicrobial Resistance and Prescribing among Physicians in a Hospital Setting in Lima, Peru. BMC Clinical Pharmacology, 15, 11-18.

[28] Reichert, S., Simon, T. and Halm, E.A. (2000) Physicians' Attitudes about Prescribing and Knowledge of the Costs of Common Medications. Archives of Internal Medicine, 160, 2799-2803. https://doi.org/10.1001/archinte.160.18.2799

[29] Geitona, M., Zavras, D., Hatzikou, M. and Kyriopoulos, J. (2006) Generics Market in Greece: The Pharmaceutical Industry's Beliefs. Health Policy, 79, 35-48. https://doi.org/10.1016/j.healthpol.2005.11.004

[30] Kareem, N., Oshikoya, A. and Awobusuyi, J. (2009) Perceptions of Doctorstoadverse Drug Reaction Reporting in a Teaching Hospital in Lagos. BMC Clinical 
Pharmacology, 9, 14. https://doi.org/10.1186/1472-6904-9-14

[31] Gallo, M., Clavenna, A., Bonati, M., Siani, P., Irpino, A., Rossi, F. and Capuano, A. (2012) Active Surveillance of Adverse Drug Reactions in Children in Five Italian Paediatric Wards. Open Journal of Pediatrics, 2, 111-117.

https://doi.org/10.4236/ojped.2012.22019

[32] Rushed, A., Wong, I., Cranswick, N., Tomlin, S., Rascher, W. and Neubert, A. (2012) Riskfactors Associated with Adverse Drug Reactions in Hospitalized Children: International Multicentre Study. European Journal of Clinical Pharmacology, 68, 801-810. https://doi.org/10.1007/s00228-011-1183-4

[33] Aagaard, L. and Hansen, E. (2010) Adverse Drug Reactions Reported for Systemic Antibacterials in Danish Children over a Decade. British Journal of Clinical Pharmacology, 70, 765-768. https://doi.org/10.1111/j.1365-2125.2010.03732.x

[34] Lee, J.H., Park, K.H., Moon, H.J., Lee, Y.W., Park, J.W. and Hong, C.S. (2012) Spontaneous Reporting of Adverse Drug Reactions through Electronic Submission from Regional Society Healthcare Professionals in Korea. Yonsei Medical Journal, 53, 1022-1027. https://doi.org/10.3349/ymj.2012.53.5.1022

[35] Impicciatore, P., Choonara, I., Clarkson, A., Provasi, D., Pandolfini, C. and Bonati, M. (2001) Incidence of Adverse Drug Reactions in Paediatric In/Outpatients: A Systematic Review and Meta-Analysis of Prospective Studies. British Journal of Clinical Pharmacology, 52, 77-83. https://doi.org/10.1046/j.0306-5251.2001.01407.x

[36] Choudhary, A., Nivedhitha, S., Radhakrishna, L., Tirumalaikolundusubrimnian, P. and Manicvasagam, S. (2013) Perception of Adverse Drug Reaction among Doctors, Nurses and Pharmacists of a Tertiary Care Rural Teaching Hospital. Internet Journal of Pharmacology, 12, No. 1.

[37] John, L.J., Arifulla, M., Cheriathu, J.J. and Sreedharan, J. (2012) Reporting of Adverse Drug Reactions: An Exploratory Study among Nurses in a Teaching Hospital, Ajman, United Arab Emirates. Daru, 20, 44. https://doi.org/10.1186/2008-2231-20-44

[38] Hasford, J., Goettler, M., Munter, K.H. and Müller-Oerlinghausen, B. (2002) Physicians' Knowledge and Attitudes Regarding the Spontaneous Reporting System for Adverse Drug Reactions. Journal of Clinical Epidemiology, 55, 945-950. https://doi.org/10.1016/S0895-4356(02)00450-X

[39] Okezie, E. and Olufunmilayo, F. (2008) Adverse Drug Reactions Reporting by Physicians in Ibadan, Nigeria. Pharmacoepidemiology and Drug Safety, 17, 517-522. https://doi.org/10.1002/pds.1597

[40] Sushma, M., Kavitha, R., Divyasree, S., Deepashri, B. and Jayanthi, C.R. (2011) A Questionnaire Study to Assess the Knowledge, Attitude and Practice of Pharmacovigilance in a Paediatric Tertiary Care Center. Journal of Chemical and Pharmaceutical Research, 3, 416-422. 
Submit or recommend next manuscript to SCIRP and we will provide best service for you:

Accepting pre-submission inquiries through Email, Facebook, LinkedIn, Twitter, etc. A wide selection of journals (inclusive of 9 subjects, more than 200 journals)

Providing 24-hour high-quality service

User-friendly online submission system

Fair and swift peer-review system

Efficient typesetting and proofreading procedure

Display of the result of downloads and visits, as well as the number of cited articles Maximum dissemination of your research work

Submit your manuscript at: http://papersubmission.scirp.org/

Or contact pp@scirp.org 